\title{
Recruitment decline in North Sea herring is accompanied by reduced larval growth rates
}

\author{
Mark R. Payne ${ }^{1,2, *, * *}$, Stine D. Ross ${ }^{1, * *}$, Lotte Worsøe Clausen ${ }^{1}$, Peter Munk ${ }^{1}$, \\ Henrik Mosegaard ${ }^{1}$, Richard D. M. Nash ${ }^{3}$ \\ ${ }^{1}$ National Institute of Aquatic Resources (DTU-Aqua), Technical University of Denmark, 2920 Charlottenlund, Denmark \\ ${ }^{2}$ Environmental Physics, Institute of Biogeochemistry and Pollutant Dynamics, ETH Zürich, Universitätsstrasse 16, \\ 8092 Zürich, Switzerland \\ ${ }^{3}$ Institute of Marine Research, PB 1870 Nordnes, 5817 Bergen, Norway
}

\begin{abstract}
The stock of North Sea autumn spawning herring Clupea harengus (L.) has shown an unprecedented 10 yr sequence of sharply reduced recruitment, in spite of a high spawning biomass. Recent work has identified this below-expected recruitment as being determined during the larval phase: however, the underlying mechanism remains elusive. In this study we analysed archived larval samples captured before and after the onset of the reduced survival to test the hypothesis of a concurrent change in the larval growth rate. Individual larval growth rates, averaged over the $21 \mathrm{~d}$ prior to capture, were estimated for 200 larvae from 4 different years using a model-based analysis of otolith ring widths. Hydrographic backtracking models complemented the otolith analysis by reconstructing the environmental history and spawning origin of each larva. A significant reduction in net larval growth rate of $8 \%$, concurrent with the reduced larval survival and recruitment, was identified: after correcting for the effect of other explanatory variables (e.g. temperature changes), the gross reduction was found to be $12 \%$. This reduction is most probably due to changes in either the amount or quality of available food. The study demonstrates the potential of coupling 2 different techniques for affording new insights into fish early life history: otolith microstructure analysis and hydrographic modelling. Finally, the study provides a novel indication of the association between reduced growth and larvae survival, thereby narrowing the range of potential mechanisms underlying the observed reduction in the recruitment of North Sea autumn spawning herring.
\end{abstract}

KEY WORDS: North Sea herring $\cdot$ Otolith microstructure $\cdot$ Hydrographic backtracking $\cdot$ Larval growth $\cdot$ Larval mortality $\cdot$ Recruitment

Resale or republication not permitted without written consent of the publisher

\section{INTRODUCTION}

In recent years the North Sea autumn spawning herring Clupea harengus (L.) stock has shown a markedly reduced production of juvenile fish (recruitment) (Payne et al. 2009). Starting from the 2002 year class, the stock has produced 10 successive weak year classes (2002 to 2011) (ICES 2012). This reduced recruitment has occurred in spite of an adult population (spawning stock biomass) that is well above the level where impacts upon the production of juveniles are expected (ICES 2012). The robustness and enduring stability of the current regime suggests that fundamental changes have taken place in the processes controlling the productivity of this stock.

The reduced productivity appears to be a consequence of reduced survival during the relatively long larval phase (from spawning in autumn until metamorphosis in late winter to early spring) (Payne et al. 
2009) (Fig. 1). Such a reduction has occurred previously, albeit over a much shorter period e.g. the 1988 to 1990 year classes (Nash \& Dickey-Collas 2005). The increased larval mortality has also been traced further back into the early life-history through analysis of field-based observations, and may occur closer to spawning than to metamorphosis (Fässler et al. 2011).

However, in spite of the insight into the dynamics of this stock and its long history of scientific investigations (Cushing \& Bridger 1966, Sinclair 2009, Dickey-Collas et al. 2010) a mechanistic understanding of the recruitment process remains elusive. Many hypotheses have been proposed; however, there is no clear consensus. Temperature increases in the North Sea have been widely reported and shown to be associated with increased larval mortality (Payne et al. 2009, Fässler et al. 2011). Bioenergetics models have suggested that the time around yolk-sack absorption and first feeding may represent a critical juncture for survival, again possibly related to temperature (Hufnagl \& Peck 2011). Changes in the zooplankton community in the North Sea are also known to have occurred (Edwards et al. 2007) and may have changed the quality or suitability of food available for North Sea herring. Parasite indicators have also suggested changes in the feeding patterns ( $\mathrm{S}$. Lusseau unpubl. data). Cannibalism by adult herring on their own larvae has also been proposed as a possible explanation (Corten 2013).

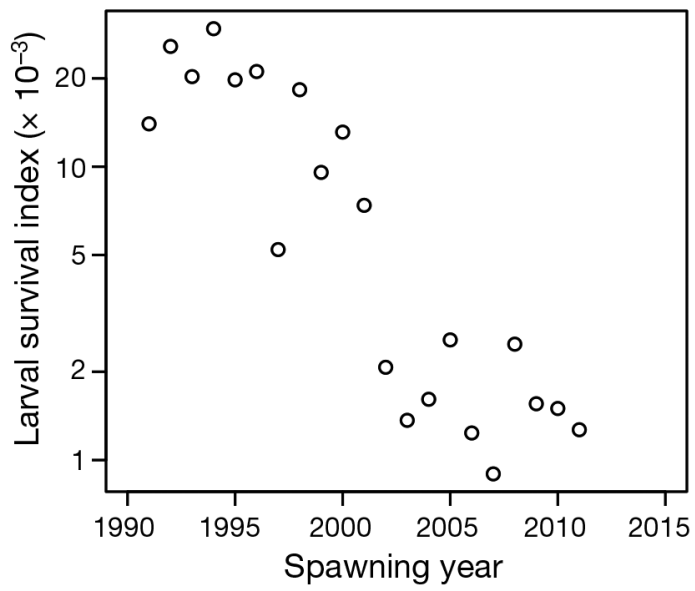

Fig. 1 Time series of larval survival index (Nash \& DickeyCollas 2005, Payne et al. 2009), defined as the ratio of the abundance of late larvae (typically $20-30 \mathrm{~mm}$, as represented by the IBTS0 index, ICES 2012) to the abundance of early larvae (less than 10-11 $\mathrm{mm}$, as represented by the SCAI index, Payne 2010, ICES 2012). Survival ratio is plotted against the year in which the larvae were spawned. Note the logarithmic scale on the vertical axis. Adapted from ICES (2012) with permission
A recurring theme amongst these hypotheses is changes in the growth rate of the larvae, either directly or indirectly. For example, changes in the zooplankton community could give rise to changes in either the quantity or quality of available food, and thereby alter the growth rate. Alternatively, changes in water temperature (assuming no changes in food) can alter the energy utilisation of individuals, leading again to changes in growth rate. Altered growth rates can then influence survival, either indirectly via size and/or growth-specific predation, or directly through starvation mortality (Leggett \& DeBlois 1994, Houde 2002). Growth, as suggested elsewhere (Anderson 1988), represents a 'rational theoretical framework' for approaching such a problem. We therefore propose the following hypothesis: The change in larval survival rate of North Sea autumn spawning herring from before 2001 to after 2001 is associated with a change in the growth rate during the larval phase.

Measuring growth rates in the field is typically challenging, and usually impossible in a retrospective manner. However, the analysis of otolith microstructure in archival collections of larvae is a powerful tool for determining life history trajectories such as somatic growth. The otolith microstructure is strongly influenced by the environmental conditions experienced during the larval phase, such as temperature (Folkvord et al. 2004) and food availability (Johannessen et al. 2000). Where feeding conditions are sufficient for growth, herring larvae can deposit daily increments on their otoliths and thus the individual larval otolith microstructure can be used as a proxy for the general growth conditions (Geffen 1982, McGurk 1984, Folkvord et al. 2000, Fox et al. 2003).

Changes in growth rates, however, need to be set in the context of the physical and biological environment in which they occur. Typically, such data can be difficult to obtain: hydrographic backtracking (Batchelder 2006, Christensen et al. 2007, Thygesen 2011), however, offers one way in which to reconstruct this information. Modern oceanographic circulation models provide estimates of the local currents and oceanographic state variables at relatively high temporal and spatial resolutions. By releasing simulated 'larvae' into these modelled fields and following them in an individual-based lagrangian manner, it is possible to produce a set of trajectories that describe the advection of these particles and the conditions they experience along the way. Furthermore, by running time backwards from a given point (e.g. the position and time where a larva was captured), it 
is possible to infer both where the larva originated and the environmental history prior to capture. Such an approach can therefore be used to produce a set of environmental parameters that may help explain observed changes in growth rates.

In the present study we combined these 2 techniques, otolith microstructure analysis and hydrographic backtracking, to test the hypothesis of a reduction in larval growth being associated with reduced productivity. We analysed the otolith microstructure of archived larvae from a North Sea sampling program to infer growth rates obtained close to the point at which they were captured. We complimented these findings with results from backtracking analyses to 'add value' to the observations in a manner that would not otherwise be possible. Finally, we applied mixed-effects modelling to combine these 2 data sources into a single analysis that allowed us to test the hypothesis in question.

\section{MATERIALS AND METHODS}

\section{Survey data and sample archive}

Late-stage herring larvae have been surveyed in the North Sea on a regular basis since 1977, and with standardised protocols since 1991 as part of the International Bottom Trawl Survey (IBTS). The survey uses a $2 \mathrm{~m}$ ring net, generally referred to as a MIK net (ICES 2006), and is undertaken between January and March each year across the entire North Sea region by a multinational fleet of research vessels. Archived ethanol-preserved larvae were available from 1995 to the present from the Danish sampling sectors of this survey. Hauls were selected for analysis to maximise the spatial coverage and to cover 2 years prior to $(1998,1999)$ and after $(2003,2004)$ the onset of the 2000s productivity reduction.

\section{Otolith analysis and profile generation}

Preserved larvae from a given haul were rinsed and measured to the nearest $\mathrm{mm}$ (rounded down). Herring larvae shrink due to death, capture and preservation. However, for the purposes of this study it was not necessary to estimate live length: preserved lengths are reported here. Individual larva were selected to ensure an even coverage of the range of lengths present within the haul. Sagittal otoliths were extracted under a dissecting microscope and mounted in thermoplastic resin (Buehler
Thermoplastic Cement no. $40-8100$ ) at $140^{\circ} \mathrm{C}$. Samples were viewed and photographed using a LeicaTM DMLB compound light microscope (transmitted light) with long working-distance objective lenses ( $20 \times$ to $126 \times$ magnification). If necessary, the otoliths were polished using a series of grinding and polishing films $\left(3 \mathrm{M}^{\mathrm{TM}}\right)$ with decreasing grain sizes from $10 \mu \mathrm{m}$ to $0.3 \mu \mathrm{m}$ to optimise the visual resolution.

An overview picture (20× magnification) was first used to obtain measurements of the major and minor axes of the otolith. Otoliths that were damaged or where it was not possible to obtain reliable measurements of both axes were discarded. A high-magnification grey-scale picture ( $80 \times$ to $126 \times$ magnification) was taken of the edge-region in the direction where the otolith radius was at its largest and the rings most easily resolved.

Increment-width profiles were derived from these pictures. The 'Caliper' tool in the ImagePro ${ }^{\mathrm{TM}} 5.0$ image analysis package was used with a profile bandwidth of $10 \mu \mathrm{m}$ and a 'falling point-of-inflection' detection criteria to provide initial measurements. Ring detection was checked by an expert reader, and obviously erroneous measurements were corrected manually. The increment widths and radial distance from the edge of the otolith were recorded. In regions where the increments were unclear, unrealistically small widths (less $0.5 \mu \mathrm{m}$ ) were reported, or there were no visible ring structures, no data was recorded. A second reader repeated the quality check procedure to minimise subjectivity. The analysis procedure was repeated for at least 2 nearly-parallel but distinct radii for each otolith to provide both redundancy and increased precision. Finally, the radial size along each of the profiles was determined from the $20 \times$ magnification picture.

\section{Otolith profile analysis}

Previous studies examining larval herring otolith microstructure have typically used a ring counting approach (e.g Munk et al. 1991, Brophy \& King 2007). Here we develop a ring width based approach to circumvent some of the problems associated with accurate ageing of herring larvae and allowing for an estimation of the associated uncertainty. The method involves first smoothing the ring width profiles for a given otolith with a spline curve in a manner that allows for systematic variation between the profiles and accounts for some of the statistical complexities (Eqs. 1 to 5 below): however, in certain cases the full 
statistical model is not required and a simplified version can be used in its place (Eqs. $6 \&$ 7). Finally, the smoothed ring width profiles are converted to growth rates averaged over a given number of rings (Eqs. 8 \& 9) for further use in the analysis.

The approach is predicated on the assumption that the relative deposition rate of material on the otolith is independent of direction. The shape of the otolith is therefore maintained during the growth process, with regions with large radii growing faster (in absolute terms) than those with smaller radii. The width of a ring, relative to the radius, is therefore constant, i.e.

$$
\frac{u_{i}(\theta)}{R(\theta)}=\omega_{i}(\theta)=\omega_{i}
$$

where $u_{i}(\theta)$ is the absolute width of ring $i$ in some arbitrary direction $\theta, R(\theta)$ is the radius of the otolith in the same direction and $\omega_{i}(\theta)$ is the relative width of the same ring. $\omega_{i}(\theta)$ is assumed to be independent of the angular direction and therefore we can simply write $\omega_{i}$ in place of $\omega_{i}(\theta)$.

However, making ring width measurements is difficult and the associated noise is expected to be large. We therefore apply a spline-smoother to these data to generate an estimate of the underlying mean ring width, and to merge measurements from separate profiles:

$$
\omega_{i m}=s\left(\frac{r_{i}}{R_{m}}\right)+p_{m}+\varepsilon_{i m}
$$

where $\omega_{i m}$ is the relative ring width of measurement $i$ in profile $m, s()$ is a spline-smoother, $r_{i}$ is the radial distance of measurement $i$ from the otolith edge, $R_{m}$ is the radius of the otolith along profile $m$, and $\varepsilon_{i m}$ is the residual error. A constant factor for each profile, $p_{m}$ is also required to allow for systematic differences in ring width between the profiles, and is defined such that it sums to zero across all profiles, i.e.

$$
\Sigma_{m} p_{m}=0
$$

Furthermore, we assume that errors in the residuals are normally distributed with a mean of zero and variance of $\sigma^{2}$, but also allow for correlation between residuals within the same profile, i.e.

$$
\begin{gathered}
\varepsilon_{i m} \sim N\left(0, \sigma^{2}\right) \\
\operatorname{cor}\left(\varepsilon_{i m}, \varepsilon_{j m}\right)=1-\exp \left(-\left(\left|r_{i}-r_{j}\right|\right) / R_{m} \tau\right)
\end{gathered}
$$

where $\varepsilon_{i m}$ and $\varepsilon_{j m}$ are residuals from 2 measurements ( $i$ and $j$ ) within the same profile $m, r_{i}$ and $r_{j}$ are the absolute radial distance from the edge between these measurements (as above), and $\tau$ is a parameter char- acterising the distance over which the correlation occurs.

This approach to analysing ring width profiles allows for both systematic deviations in the growth rate at different angles in the otolith (the $p_{m}$ factor) and auto-correlative structures in the results. In cases where such corrections are not required, the $p_{m}$ and $\tau$ parameters will go to zero and the model will simplify to a smoother with independent residuals, i.e.

$$
\begin{aligned}
& \omega_{i}=S\left(\frac{r_{i}}{R}\right)+\varepsilon_{i} \\
& \varepsilon_{i} \sim \mathrm{N}\left(0, \sigma^{2}\right)
\end{aligned}
$$

Mean growth rates over a given period can be determined from the smoother, $s()$, by solving for the relative distance from the edge, $\rho$, at which the integrated number of rings, $n$, are to be found, i.e.

$$
n=\int_{0}^{\rho} \frac{1}{s(\lambda)} \mathrm{d} \lambda
$$

where $\lambda$ is a dummy variable of integration. Eq. (8) can be understood as integrating the ring density (i.e. the inverse of the smoothed ring widths) over the interval $[0, \rho]$ to estimate the number of rings in this interval. However, we wish to invert this expression and find the estimated width of the first $n$ rings in from the edge: this requires numerical solution of Eq. (8) for a given $n$ to find $\rho$. Finally, the mean absolute

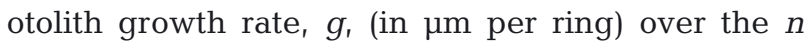
rings from the edge can then be calculated as follows:

$$
g=\frac{\rho R}{n}
$$

where $R$ is the mean radius of the otolith (i.e. mean of the major and minor axes).

The number of rings over which the growth rate was averaged was chosen once all samples had been analysed, based on a trade-off between 2 constraints. On the one hand, using too few rings incorporated a substantial amount of the otolith edge, where the rings are poorly defined and estimates uncertain. On the other hand, the total number of rings visible in each photograph was variable and setting the number of rings too high excluded samples that contained fewer rings. The final value was therefore chosen to maximise the number of valid samples, whilst also maximising the number of rings over which growth was averaged.

Uncertainties in the smoothed estimate of the mean ring width, $s()$, were generated as part of the smoothing procedure and propagated through the calculations in the standard manner. All smoothing calcula- 
tions were performed using the 'mgcv' package in $\mathrm{R}$ (Wood 2006). Following the recommendations of Wood (2006), a spline 'gamma' parameter of 1.4 was employed to avoid overfitting of the data.

\section{Hydrographic backtracking}

The otolith-derived larval growth estimates were complemented with additional data derived through the use of hydrographic backtracking techniques. The theory underpinning this technique has been detailed elsewhere (Batchelder 2006, Christensen et al. 2007, Thygesen 2011). Briefly, a set of particles representing larvae are 'released' in an oceanographic circulation model at an appropriate point in time and space. The particles are treated as lagrangian tracers and transported according to the local (modelled) currents and turbulence. When running in a backtracking mode, time is run backwards and therefore the trajectories generated are indicative of the source of the particles, rather than their destination.

A backtracking analysis was performed for each haul from which larval otoliths were analysed. The particle tracking was performed using the Individual Based Modelling library (IBMlib: A Christensen, M. Payne, P. Mariani) forced with hourly $10 \mathrm{~km}$ resolution physical fields from the Norwegian Ecological Model System (NORWECOM) for the North Sea (Aksnes et al. 1995, Skogen et al. 1995, Skogen \& Søiland 1998). For each haul, 10000 particles were released uniformly throughout the upper $60 \mathrm{~m}$ of the water column at the date and position of capture and tracked backwards in time until the previous 1 July: the water temperature experienced by the larvae, photoperiod (number of daylight hours) and the spatial position were stored at daily intervals.

Particles were treated as passive tracers with no imposed behaviour in either the horizontal or vertical directions. However, a simple constraint was imposed that forced the particles to remain in the upper $60 \mathrm{~m}$ of the water column, consistent with observations (Heath et al. 1988): if the particle was advected below this depth, it simply 'swam' back to $60 \mathrm{~m}$. The North Sea is unstratified during winter (the season these simulations occurred) and therefore the water column is generally homogenous: the effect of the vertical distribution and possible migratory behaviour was not expected to be large. Furthermore, the herring larvae used in this study were typically less than $40 \mathrm{~mm}$ in length and therefore do not exhibit active schooling behaviour (Gallego \& Heath 1994); the assumption of passive horizontal behaviour therefore also appears justified. Particle trajectories were therefore independent of larval size: it was therefore sufficient to generate a single set of trajectories for each haul, and apply the same set for each larva analysed from that haul.

Trajectories were analysed and used to assign a most likely spawning location to the larvae sampled by a given haul. This was necessary since there could be inherent differences in the growth characteristics for each of the components or sub-stocks (Heath et al. 1997). Five potential spawning regions and times were defined based on larval surveys of the spawning grounds (i.e. the International Herring Larval Survey (IHLS), Heath 1993). For a given haul and point in time, the proportion of particles in each of the spatial spawning regions was calculated and these proportions then averaged over the duration of the corresponding spawning period. The resulting value was then interpreted as a proxy of how many of the larvae observed in the haul originated from each potential spawning ground: all larvae in each individual haul were then assigned a most likely spawning origin based upon the component that contributed the largest fraction.

\section{Data analysis}

The central hypothesis of this work was tested using linear mixed-effects modelling. Estimates of otolith growth were matched with variables derived from the hydrographic backtracking to provide a detailed description of the individual larva and the environment that it recently experienced. The modelling procedure followed a backward selection approach, starting from a multiplicative 'beyondoptimal' model (sensu Zuur et al. 2009), incorporating all fixed and random effects, i.e.

$$
\begin{gathered}
\log \left(g_{i}\right)=\underline{\beta}_{\underline{a}} \underline{a}_{i}+b_{j}+\varepsilon_{i} \\
b_{j} \sim N\left(0, \sigma_{\text {haul }}^{2}\right) \\
\varepsilon_{i} \sim N\left(0, e_{i}^{2} \sigma_{\text {resid }}^{2}\right)
\end{gathered}
$$

where $g_{i}$ is the mean otolith growth rate of larva $i, a_{i}$ is the vector of fixed effects and $\beta$ is the vector of coefficients. The fixed effects considered here were the length of the preserved larvae, the mean temperature experienced during the period leading up to capture, the mean photoperiod during this time (a proxy of feeding potential), the year and the day of the year in which the larvae was captured, and the spawning component where it originated. $b_{j}$ is a ran- 
dom effect for haul $j$ (i.e. the haul that larva $i$ was captured in), assumed to be distributed normally with a mean of zero and variance $\sigma_{\text {haul }}^{2} . \varepsilon_{i}$ is the residual, assumed to be normally distributed with a mean of zero and variance $e_{i}^{2} \sigma_{\text {resid }}^{2}$, where $e_{i}$ is the relative uncertainty in the estimated growth rate $\left(g_{i}\right)$ and $\sigma_{\text {resid }}^{2}$ is a parameter to scale this variance accordingly.

The random effects elements of the model were tested using likelihood ratio tests based on models fitted by Restricted Maximum Likelihood (REML) (Zuur et al. 2009). Refinement of the fixed-effects component was performed using both marginal F-tests (based on REML fits) (Pinheiro \& Bates 2000) and Likelihood-ratio tests (based on Maximum Likelihood (ML) fits) (Zuur et al. 2009) in parallel. The final model, fit using REML, was assessed using standard model diagnostic tools. All mixed-effects models were fitted using the 'nlme' package in $\mathrm{R}$ (Pinheiro \& Bates 2000).

\section{RESULTS}

\section{Larval otoliths}

Larvae were processed following the procedures detailed above. The spatial coverage of the samples was constrained by the distribution of the larvae present in the archival collection: typically, the Danish component of the IBTS survey is restricted to a broad swath across the central North Sea, and this is reflected in the samples analysed here (Fig. 2a). Larval samples covered 2 consecutive years prior to the onset of the recruitment failure $(1998,1999)$ and 2 consecutive years after the onset $(2003,2004)$ (Fig. 2b). Larvae were selected from within a haul to cover the range of length classes present. The usable samples ranged between 20 and $40 \mathrm{~mm}$ in length, with the majority between 25 and $35 \mathrm{~mm}$ and the median being $30 \mathrm{~mm}$ (Fig. 2c). In total, usable ring width profiles were obtained for 197 larvae and used for further processing.

Larval otolith morphology showed a strong relationship to the length of the preserved larvae. The size of the otoliths (defined here as the mean of the major and minor radii) was significantly and positively correlated with the length of the larvae (Fig. 3a; slope $=14.7 \pm 1.0 \mu \mathrm{m} \mathrm{mm}^{-1}, R^{2}=0.81, t$-test for positive slope: $\mathrm{p}<0.001$ ). We therefore assume changes in otolith size to be an appropriate conservative proxy for changes in the length of the larvae (and therefore growth rates) in this size range.

Otolith shape also changes with increasing larval length (Fig. 3b). The eccentricity (ratio of the major to minor axes) of the otoliths in the smallest larvae was minor (less than 10\% difference); however, beyond 25 to $30 \mathrm{~mm}$, the larval otoliths started to elongate appreciably. A break-point regression model, where the eccentricity is constant below the breakpoint and increases above, suggested that this change occurred around 26 to $27 \mathrm{~mm}$. Changes in the shape of the otolith may affect the relationship between the size of the otolith and the size of the larvae. However, both visual inspection (e.g. from Fig. 3a) and statistical tests (quadratic vs. linear model, likelihood ratio test: $\mathrm{LR}=4.014, \mathrm{df}=1, \mathrm{p}=0.045)$ suggested that deviations from linearity were minor and only weakly
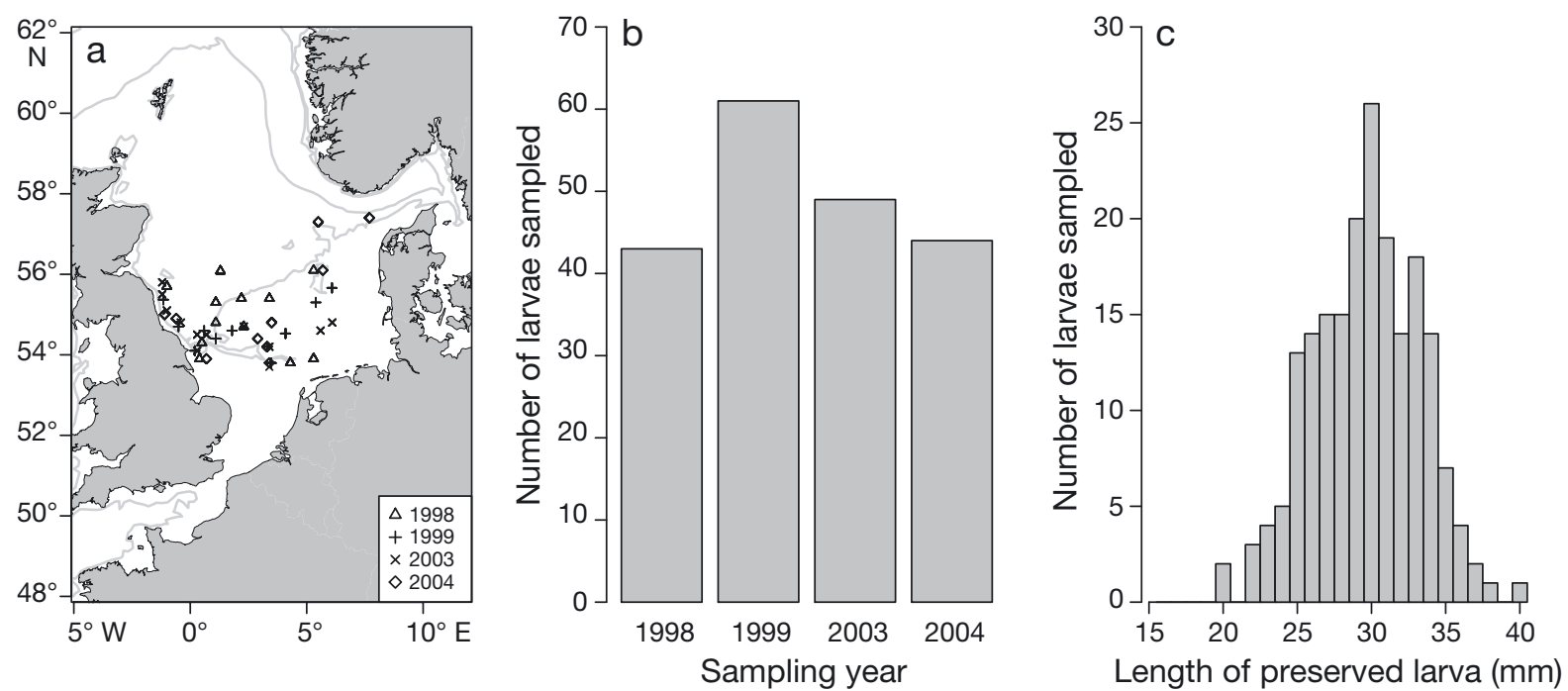

Fig. 2. Distribution of larval samples. (a) Spatial distribution of samples, grouped by year. (b) Distribution of samples taken between the 4 sampling years. (c) Distribution of samples across larval lengths 


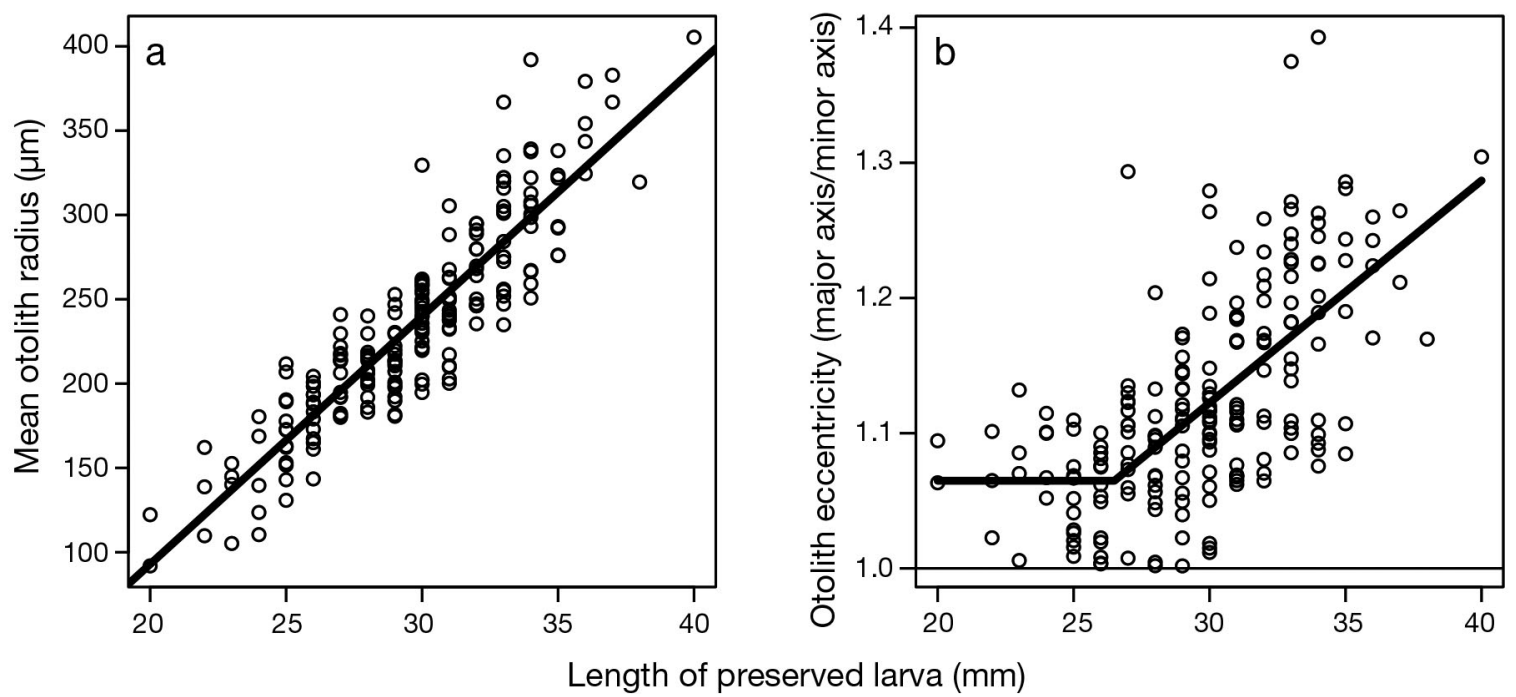

Fig. 3. Relationship between otolith size and shape, and length of preserved larvae. (a) Mean otolith radius as a function of measured larval length, with fitted linear regression. (b) Changes in otolith shape visualised by plotting the eccentricity of the otolith (size of the major axis divided by the size of the minor axis) against the size of the larva. Line shows a break-point regression fit to the data, with the optimal break point at around $26.5 \mathrm{~mm}$

supported. Therefore, there is little support for a deviation from the assumption of a linear otolith-sizelarval-length relationship. Changes in larval otolith size and growth can therefore reasonably be interpreted as changes in larval length.

\section{Otolith-based growth estimation}

The otolith ring width approach employed here appears to be capable of handling noisy and missing ring width measurements. Most of the otolith photographs exhibited regions where it was not possibly to clearly define rings due to irregularities in the ring formation process, the presence of dust, air bubbles or other contaminants on the mounted sample, or variations in the focal plane (e.g. Fig. 4). However, the use of multiple ring width profiles along nearly parallel axes added an extra source of information in the obscured regions that could be utilised by the smoothing model applied here (Fig. 5a). The spline-smoother also handled regions around the otolith edge, where it is frequently not possible to measure rings. The smoother extrapolates into this region, based on trends in regions where there are data, but also increases the

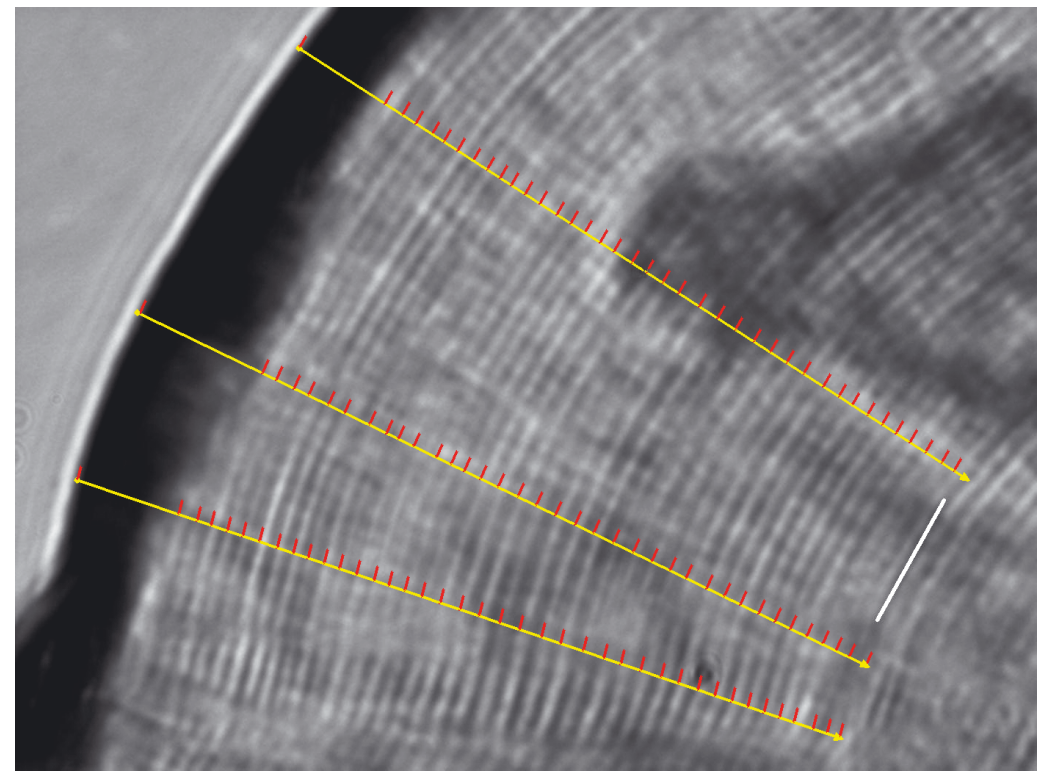

Fig. 4. Example of a larval otolith edge picture with 3 marked profiles (yellow lines) and identified ring increments (red marks). The dark arc is otolith edge; air bubbles and imperfections are also apparent

uncertainty associated with the extrapolated ring widths (Fig. 5a).

The structure of the smoothing model permits complex processes in the data to be handled, e.g. autocorrelation in the residuals, and systematic differences in ring widths between profiles (Eqs. 2 to 5). In around $45 \%$ of cases, the Aikaike Information Criteria (AIC) suggested that these extra terms were 


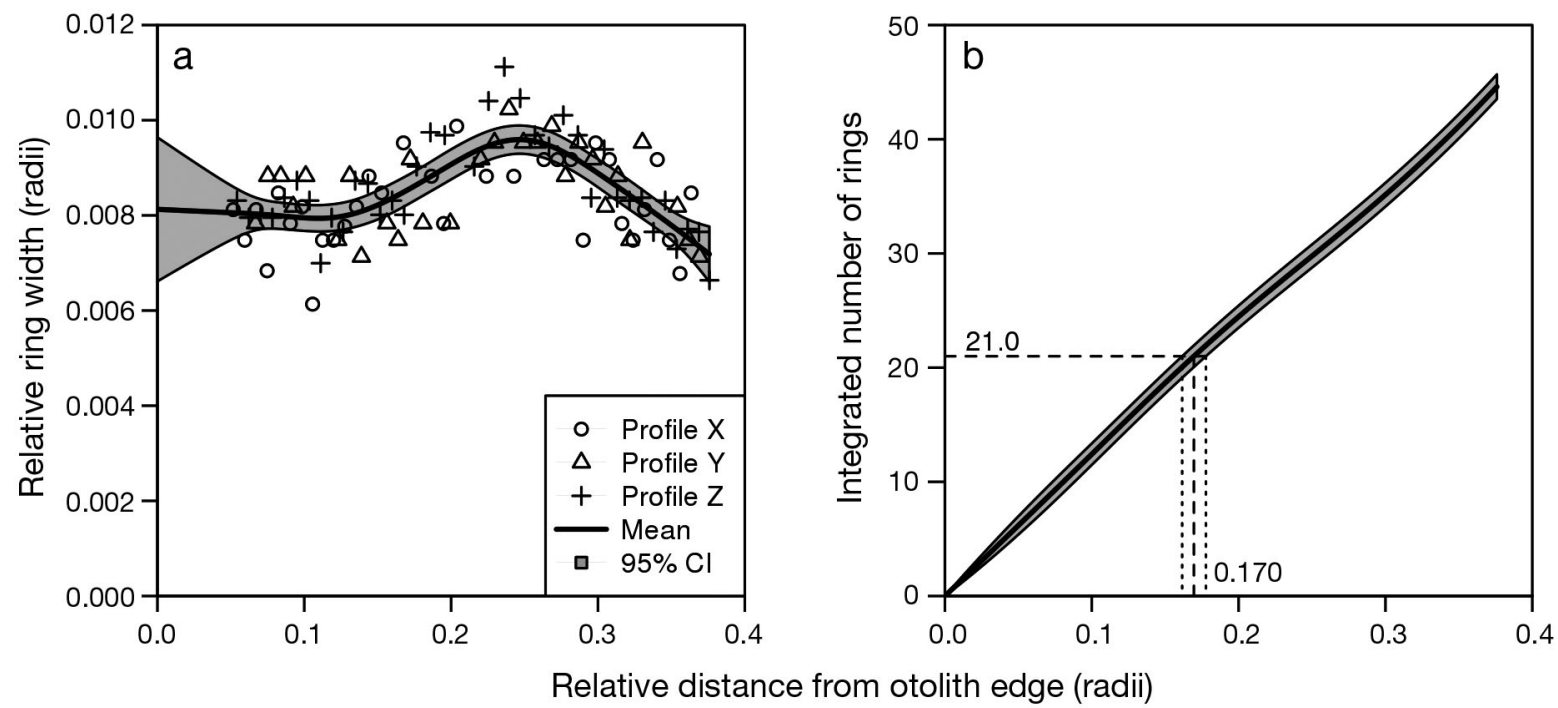

Fig. 5. Estimation of otolith growth for the picture shown in Fig. 4. (a) Relative ring widths (normalised by the radius of the otolith in the corresponding direction) are plotted as a function of the relative distance from the edge of the otolith (normalised in the same manner). The spline-smoothed mean relative ring width (thick black link) is shown together with the associated $95 \%$ confidence intervals (grey area). (b) Integrated number of rings as a function of relative distance from the otolith edge (thick black line: mean, grey area: 95\% confidence interval). The relative growth over a given period (in this example, 21 rings) and associated confidence interval is estimated by reading off the corresponding value from the horizontal axis (in this case 0.170 radii)

superfluous (Zuur et al. 2009), with a simple splinesmoother (Eq. 6) representing the data equally well. The full model (Eq. 2) was nevertheless employed in all cases for reasons of consistency: in situations where the extra terms were not needed, their coefficients reduced to effectively zero and therefore did not influence the model fit. All fits were checked visually using standard modelling diagnostics (quantile-quantile plots, residual distribution plots, autocorrelation functions): in all cases the model of the ring width profiles appeared appropriate.

Smoothed ring width profiles were used to generate estimates of otolith-growth rates by integrating and solving the ring density profile (Eq. 9; Fig. 5b). Nearly all otolith edge pictures contained sufficient information to estimate the rate of otolith growth in at least the first 21 rings before the edge (i.e. prior to capture); samples with fewer analysed rings were excluded from the final analysis.

\section{Hydrographic backtracking}

Hydrographic backtracking models provided additional information about the recent history of the larvae. Trajectories generated by tracking particles backwards in time provided a distribution of potential trajectories that could lead to the point where each larva was captured (e.g. Fig. 6a), allowing the identification of the spawning component where the larva originated (Fig. 6b). Furthermore, environmental history data such as the mean temperature (Fig. 6c) and the mean photoperiod (Fig. 6d) were also generated in the process.

The backtracking results gave insight into the larvae analysed. The majority of the larvae (80\%) sampled in this study were from the central Banks and Buchan spawning components, with just $10 \%$ coming from each of the Downs and Orkney-Shetland components (Fig. 7a). Mean temperatures prior to capture differed between larvae by up to $3{ }^{\circ} \mathrm{C}$ (Fig. $7 \mathrm{~b}$ ) and mean photoperiods by up to $1.5 \mathrm{~h}$ (Fig. $7 \mathrm{c}$ ). The differences in these parameters suggested that there were systematic environmental differences between larvae hauls that needed to be accounted for in later stages of the analysis.

\section{Data analysis}

Preliminary data exploration examined the data collected with a view to undertaking linear modelling and followed the protocol suggested by Zuur et al. (2010). Significant co-linearity was found between photoperiod and day of collection $\left(R^{2}=0.85\right)$ : day of collection was therefore dropped from the analysis in favour of the more readily interpreted photoperiod. Interactions between variables were examined (Zuur 

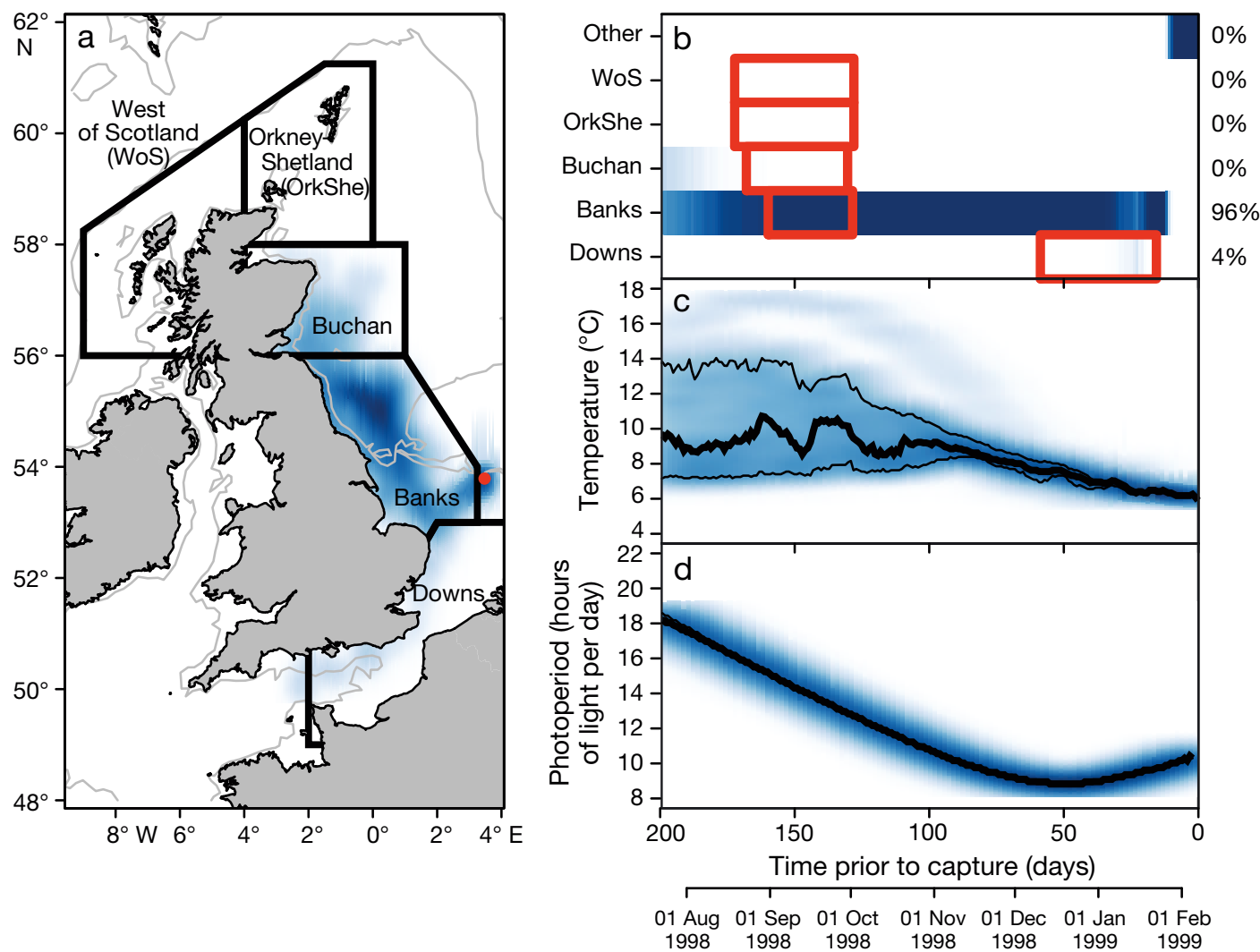

Fig. 6. Reconstruction of environmental history for the larva shown in Fig. 4 using hydrographic backtracking. (a) Density of back-tracked particle trajectories (blue colouring: darker shades indicate a higher density) released from the position of larval capture (red dot). The 50 and $200 \mathrm{~m}$ isobaths are shown for reference (light grey lines). Thick black lines denote the spatial regions associated with each spawning component. (b) Assignment of larvae to a spawning component: darker blues indicate a higher proportion of larvae. The known spawning periods of each component are indicated by the red boxes and the estimated contribution of each component to a haul is indicated at right - this larva is clearly of 'Banks' origin. (c) Temperature history of the larvae; median value (thick black line) and central 95\% confidence region (thinner black lines). (d) Photoperiod (daylight hours per day) experienced by the larva
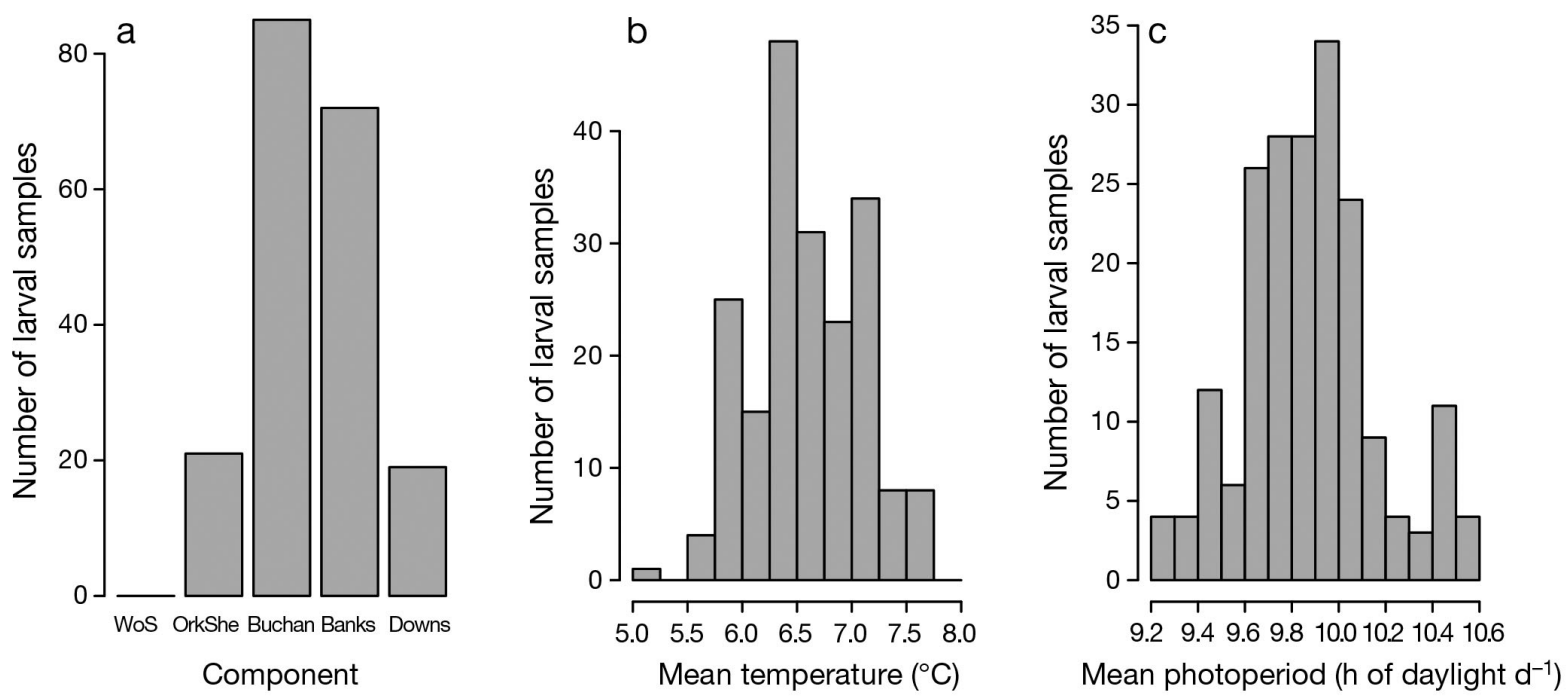

Fig. 7. Summary of the backtracking results for all sampled larvae. (a) Number of larvae assigned to each of the spawning components. WoS: West of Scotland; OrkShe: Orkney-Shetland. (b) Distribution of estimated mean temperatures for each larva during the $21 \mathrm{~d}$ prior to capture. (c) Distribution of mean photoperiods (hours of daylight per day) estimated for each larva during the $21 \mathrm{~d}$ prior to capture as estimated from backtracking 
et al. 2010) but there was no visual evidence to support their presence. Furthermore, the data available is highly unbalanced (cf. Fig. 7a), and is sparse or lacking for the interaction between some parameters: interactions were therefore not considered further.

The otolith growth data was analysed using a linear mixed-effects model (Pinheiro \& Bates 2000, Zuur et al. 2009). The initial model used log-growth rate as the response variable, with 5 explanatory variables (fixed effects: a linear dependence on each of temperature, larval length, and photoperiod with year and spawning component as factors), haul as a

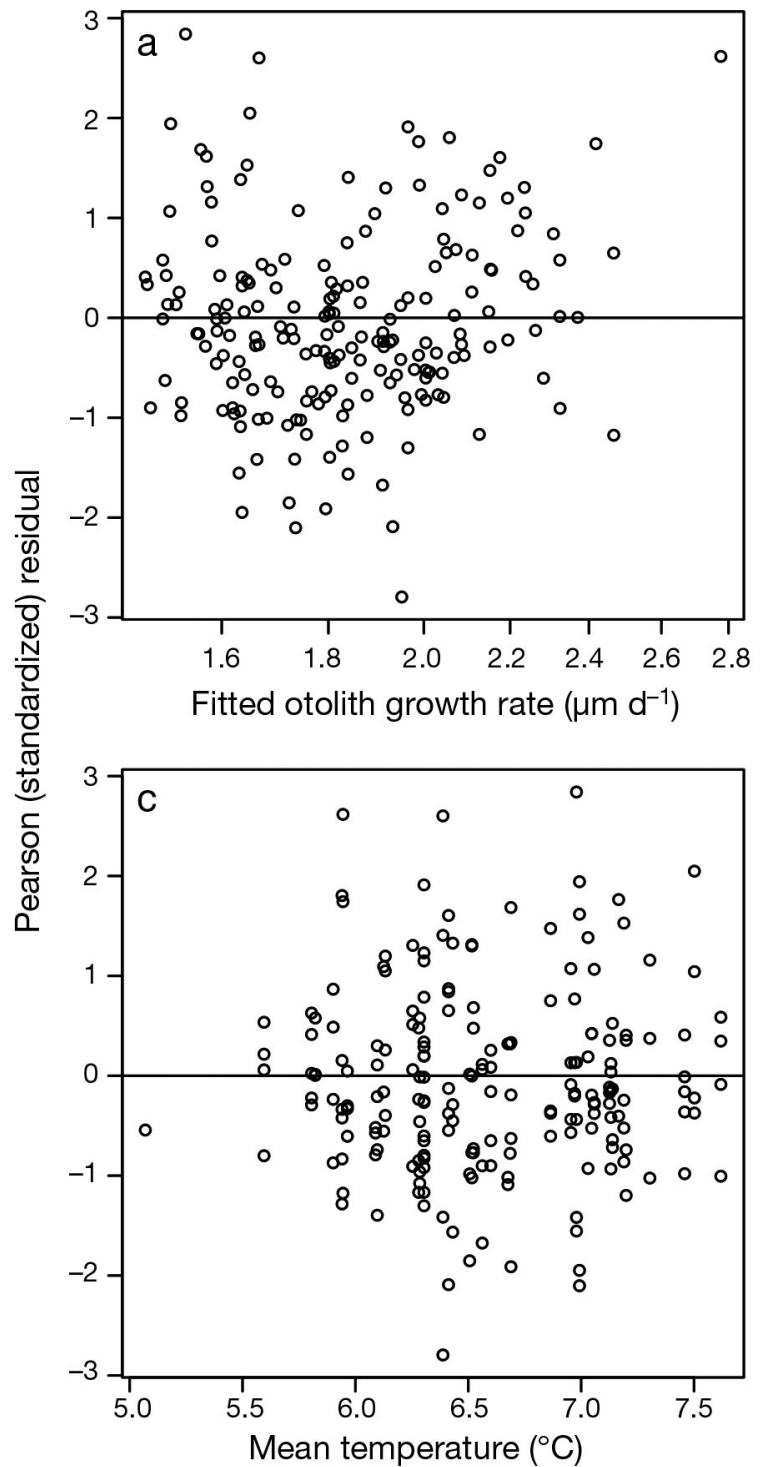

Table 1. Fixed-effect coefficients of the final model, where the log growth rate is modelled as a function of larval length $(\mathrm{mm})$, temperature $\left({ }^{\circ} \mathrm{C}\right)$, and the year. SE: standard error; df: degrees of freedom

\begin{tabular}{|lclrrr|}
\hline Variable & Value & SE & df & $t$-value & p-value \\
\hline Larval length & 0.020 & 0.004 & 152 & 5.22 & 0.000 \\
Temperature & -0.10 & 0.03 & 40 & -2.81 & 0.008 \\
Year 1998 & 0.61 & 0.04 & 40 & 16.67 & 0.000 \\
1999 & 0.58 & 0.03 & 40 & 17.16 & 0.000 \\
2003 & 0.44 & 0.04 & 40 & 12.47 & 0.000 \\
2004 & 0.53 & 0.04 & 40 & 14.03 & 0.000 \\
\hline
\end{tabular}

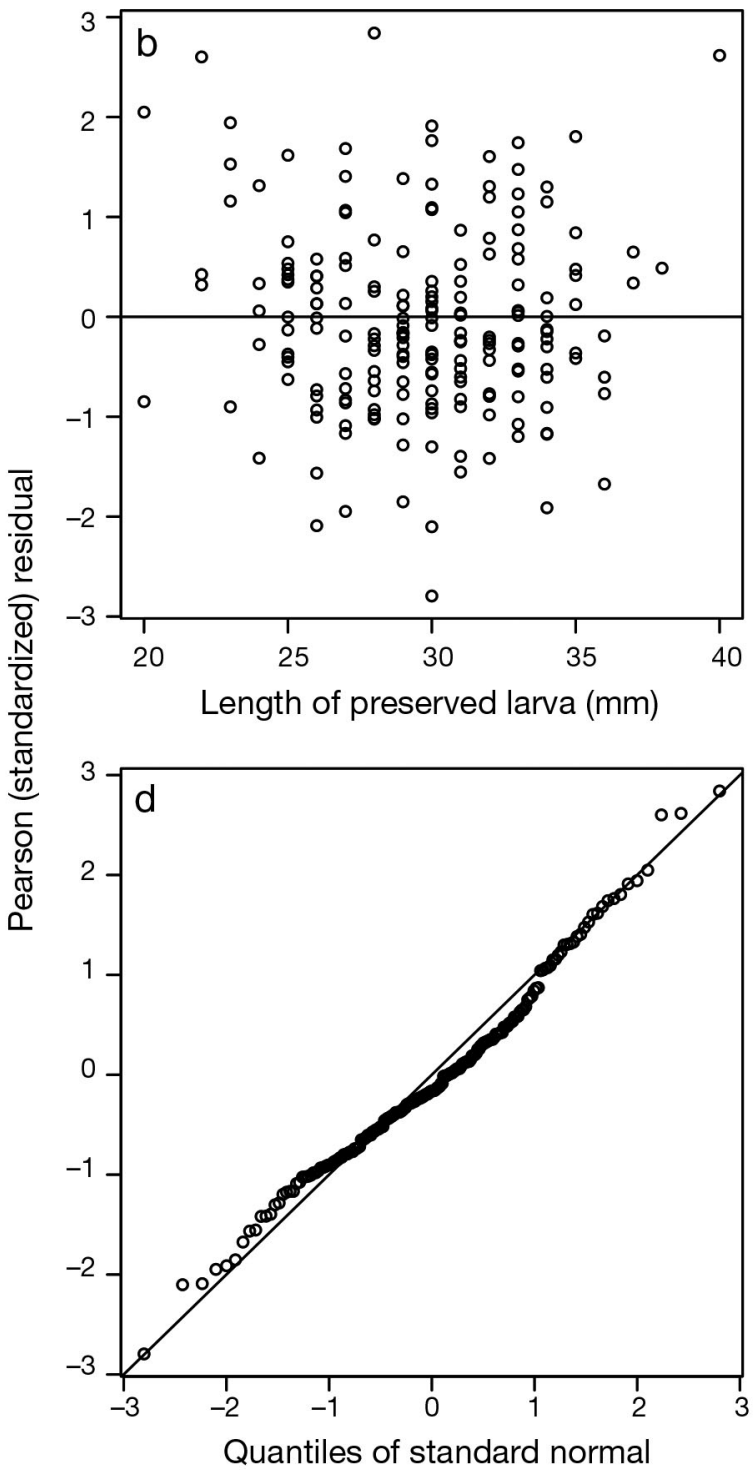

Fig. 8 Mixed-effects model diagnostics. (a) Tukey-Anscombe plot, plotting the Pearson (standardised) residuals from the model against the fitted value of the otolith growth rate (note logarithmic scale). ( b) Pearson residuals plotted as a function of larval length. (c) Pearson residuals plotted as a function of the mean temperature $\left({ }^{\circ} \mathrm{C}\right)$ experienced prior to capture. $(\mathrm{d}) \mathrm{Quan}$ tile-Quantile $(\mathrm{QQ})$ plot, plotting the Pearson residuals against the corresponding quantiles of a standard normal distribution 
random effect and the relative uncertainties in the growth-rates as (inverse) weighting factors (Eq. 10). The random-effects component was found to be necessary (Likelihood ratio test, corrected for testing on the boundary: $\mathrm{LR}=8.60$, df $=1, \mathrm{p}=0.002$ ). Refinement of the fixed-effects part of the model dropped the photoperiod and spawning component terms, retaining length, temperature and year as significant terms (Table 1). Model diagnostics of this final model showed an excellent fit to the data: the residuals appeared to be independent of the fitted growth rate (Fig. 8a), the length of the preserved larvae (Fig. 8b), the mean temperature (Fig. 8c), and the photoperiod, year and spawning component (not shown) and appeared to be homoscedastic (constant variance) in all cases. Furthermore, both the residuals (Fig. 8d) and the random-effects (not shown) appeared normally distributed. The model therefore appears to fit the data well.

The coefficients of the mixed effects model (Table 1) give insight into the factors affecting the larval growth rates. The growth rate was higher for larger larvae and lower temperatures, both of which were significant $(\mathrm{p}=0.01)$. The year effect was also significant (marginal $F$-test based on a REML fit: $F=$ 4.64, df $=3,40, \mathrm{p}=0.007$ ), suggesting a significant inter-annual variability in growth, even after the other factors had been accounted for.

Furthermore, there was a systematic pattern to the year effect: years prior to the onset of reduced recruitment $(1998,1999)$ appeared to have a consistently higher year-factor than those after the onset (2003, 2004) (Table 1). Simplifying the final model to test this observation (i.e. replacing the 'year' factor with a 'period' factor) did not result in a significantly worsened fit (Likelihood ratio test based on $\mathrm{ML}$ fit: $\mathrm{LR}=4.14$, $\mathrm{df}=2, \mathrm{p}=0.13$ ), implying that this was a valid simplification. The effect for the 2003 to 2004 period was $12 \%$ lower than the 1998 to 1999 period (one-sided $t$-test based on REML fit: $t=3.10, \mathrm{df}=42, \mathrm{p}=0.002$ ).

Finally, comparing the contributions of inter-annual variations in temperature with the year effects suggested that the year effect was the stronger of the two. As highlighted above (Fig. 7b), there were notable differences in temperatures experienced by the larvae during different years, which in turn likely influenced the growth rate. The mean temperature experienced by all the larval samples in each year was therefore used with the fitted model to predict the relative growth rate of an 'idealised' larva in each year, and the contribution of each term (Fig. 9). The inter-annual effect of temperature variations caused an increase in the growth rate of $3 \%$ from before to after the onset of reduced productivity, whereas the year effect was associated with a gross reduction in growth of $12 \%$ : the combination of the 2 effects resulted in a net reduction of $8 \%$. The year effect is therefore clearly the stronger and more important of these 2 factors.

\section{DISCUSSION}

In this study we have shown a significant reduction in the recent (i.e. within the $21 \mathrm{~d}$ prior to capture) growth rate of herring late larvae in the North Sea from 1998/1999 to 2003/2004 over and above the changes accounted for by the explanatory variables considered here. This reduction coincides with the reduction in larval survival rates, and therefore with the reduced recruitment experienced in this stock. However, interpretation of these results is not straightforward and requires careful consideration.

Firstly, it is necessary to reflect on the meaning of the statistical model and its coefficients. The model developed here attempts to explain the observed otolith growth rates in terms of a number of covariates (length, temperature, photoperiod, spawning component) that are thought to influence growth. Other inter-annually varying effects that were not included in the analysis but that could contribute to the inter-annual variability, such as the amount or quality of food available to the larvae or predation, end up being grouped into the year effect. The year

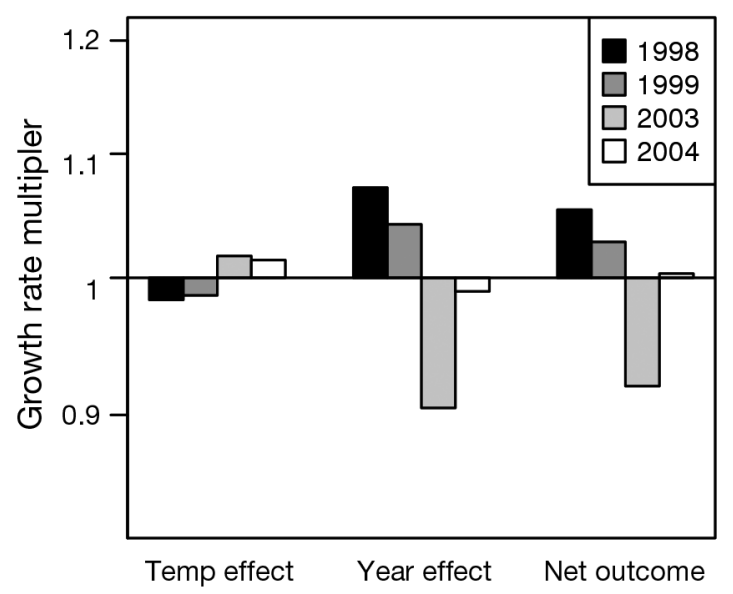

Fig. 9. Individual contributions of the year and temperature effects to the relative growth rate for the individual years. The temperature effect is calculated using the average values for that year. Model coefficients are expressed as relative values, i.e. the multiplicative effect that they have on the growth rate relative to the mean effect. Note logarithmic scale on the vertical axis 
coefficients (Table 1, Fig. 9) therefore represent the 'residual variability', once the other processes have been taken into account. Here we have shown that these processes dominate over (inter-annual) temperature changes, and encapsulate a significant reduction in growth that cannot be explained by the covariates that we have considered. Comparing growth rates before and after the onset of the reduced recruitment, we see that temperature changes have increased the growth rate by $3 \%$, but the year effect has decreased growth by $12 \%$, resulting in a net reduction in growth rate of $8 \%$ (Fig. 9).

Secondly, our results are based on the surviving larvae: large numbers of larvae died before the survey took place and hence were not sampled for this analysis. We make the (implicit) assumption that the sampled larvae are representative of the entire population of spawned larvae, yet, by the very fact that they survived long enough to be sampled, they are in fact outliers themselves. Changes in the growth rates of these survivors may-or may not-reflect the hidden processes occurring at the population level.

Otolith microstructure analyses are often predicated on the assumption that one otolith ring corresponds to one day of growth, in spite of ample evidence that this assumption may not hold all of the time (Geffen 1982, Fox et al. 2003). However, as our analysis does not hinge upon this assumption, the approach employed here is expected to be robust for this study's needs. The approach used here combined 2 different sources of data with different temporal scales. Otolith microstructure measurements estimated the average growth rate over a period of 21 rings prior to capture whereas the hydrographic backtracking work averaged the temperature and photoperiod over a period of $21 \mathrm{~d}$ prior to capture. However, as both methods are averaging over a wide temporal window that is roughly comparable, deviations from the one-ring-per-day assumption can therefore be expected to have a relatively minor impact on the rest of the analysis.

Another related assumption is that otolith growth rate is a suitable proxy for fish growth rate. This assumption also has its limitations since otoliths appear to more conservatively retain their growth than fish soma does (Mosegaard et al. 1988). The observed variation in otolith growth rates may therefore actually reflect an even higher variation in larval growth rates.

The conclusions drawn here are also naturally limited by the nature of the larval samples analysed. We have only considered 2 years before and after the onset of the reduced-recruitment regime; adding other years would improve the analysis. Furthermore, our results are strongly biased towards larvae from the Buchan and Banks components that were captured in the central North Sea. Our analysis did not show a significant difference in growth between the spawning components, but it is also possible that we do not have enough samples to detect such a difference. Similarly, we have only considered larvae from the central North Sea: other regions display different growth environments and dynamics (Munk et al. 1991, Heath et al. 1997, Payne 2010). Interactions between factors were also not considered, due to the limited coverage of the samples. Expansion of both the temporal and spatial coverage of the larval samples is therefore necessary to increase both the generality and the statistical power of this result.

We can consider the potential mechanisms that may lead to the reduction in the observed growth rate. Changes in the food supply could give rise to the observed results. If we assume a reduction in the amount or quality of the food available for herring larvae after the onset of the reduced-recruitment regime, then we would expect, on average, there to be an increased risk of starvation (especially during the winter months). Elevated starvation mortality would lead to a reduction in the total number of survivors (i.e. recruitment) and those that survived would exhibit a reduced growth rate, consistent with observations.

Furthermore, there is evidence that the food supply may have changed. Substantial changes in the plankton community are known to have occurred in the North Sea in the late 1990s and early 2000s (Weijerman et al. 2005, Edwards et al. 2007, Alvarez-Fernandez et al. 2012). However, these analyses typically examined the entire plankton community as a whole and as a consequence may have placed emphasis on changes that are not relevant to herring, or overlooked changes that are. For example, the importance of micro-zooplankton in the diets of larvae has received little attention (Montagnes et al. 2010) even though some studies indicate this fraction of the plankton community may be important in the diets of herring larvae (de Figueiredo et al. 2005, Friedenberg et al. 2012). Unfortunately there are no detailed studies specifically targeting the western and central North Sea which would indicate whether this portion of the plankton community has changed in abundance through the various planktonic regime shifts. However, there is a suggestion that changes have occurred in the UK shelf seas with the latest reduction in abundance of tintinnids (loricate ciliates) occurring from 2003 onward (Hinder et al. 2012). The 
importance of changes in microzooplankton availability for the feeding and growth of North Sea herring larvae needs further investigation.

Reduced growth rates can also increase mortality even when starvation is not important. Larval mortality is generally recognised as being lengthdependent (the 'big-is-better' hypothesis; Leggett \& DeBlois 1994, Houde 2002), with increasing mortality rates at smaller sizes. Reductions in growth rate can therefore give rise to an increased amount of time being spent in a smaller length class, and therefore a greater exposure to predators (the 'stage-duration' hypothesis, Houde 2002). An overall reduction in growth rate could therefore lead to an increase in predation mortality and a reduction in recruitment (with those that survive growing slower), also consistent with observations.

Direct changes in the predation pressure also need to be considered as an alternative mechanism. An increase in a predator population or an influx of new predatory species could easily increase the predation pressure on the larvae and reduce the numbers of larvae that survive. However, an increase in predation mortality would tend to favour survival of the faster growing larvae, thereby increasing the observed growth rate of the survivors: as this outcome is in contrast to the observations at hand, there is therefore little support for this hypothesis.

The magnitude of the changes in growth rate appears sufficient to induce the observed reduction in larval survivorship. Although at first inspection an $8 \%$ reduction in net growth rate may not appear to be particularly large, it is important to remember that the mortality rates experienced by larval populations are extremely high. A reduction in growth rate of $\sim 10 \%$, and therefore a similar increase in the amount of spent exposed to predation pressure, could easily be multiplied up to a several fold increase in net mortality. A simple calculation using the larval size data supports this. Fässler et al. (2011) estimated daily larval mortality rates between 0.05 and $0.4 \mathrm{~d}^{-1}$ for early herring in the North Sea, with substantial variation between year and spawning components. Assuming a mortality value of $0.1 \mathrm{~d}^{-1}$ and that metamorphosis occurs at a fixed length and typically takes approximately 6 mo, a $10 \%$ reduction in growth rate (and thereby $10 \%$ more days exposed to high larval mortality rates) results in an $80 \%$ reduction in the number of larvae surviving to metamorphosis. Fässler et al. (2011)'s work is based on early larvae and may therefore be an overestimate of the mean mortality experienced during the larval phase; however, halving the average daily rate over the larval period to
$0.05 \mathrm{~d}^{-1}$, in line with other studies (McGurk 1986, Kiørboe \& Munk 1986, Pepin 1991), still results in a $60 \%$ reduction in the number of surviving larvae. The magnitude of the reduction in growth rate observed here therefore appears to be consistent with the magnitude of changes in survivorship seen at the population level (Fig. 1).

Interestingly, these results imply that inter-annual temperature variability is less important than other sources of variation. Several studies (Payne et al. 2009, Hufnagl \& Peck 2011, Fässler et al. 2011) have suggested that changes in temperature between the 2 periods have had a determining role. However, this present study does not support that hypothesis: the inter-annual variation in growth rate due to temperature is markedly less than that due to the year effects. The implication is therefore that other inter-annually varying processes not captured in this work are associated with greater variability, and are therefore more likely to be important.

Changes in the food supply therefore appear to be a likely candidate mechanism. However, the simplicity of this reasoning may not reflect the complex reality of life in the ocean, and many other processes can be envisaged. Predation in particular is almost certainly not as simple as it is characterised here, and complex interactions can readily arise from the temporal and spatial overlap between species and the interaction between prey-size and predator. Nevertheless, these mechanisms are useful for generating hypotheses and can readily form the basis for future investigations.

\section{CONCLUSIONS}

The results gathered here give a unique insight into the processes influencing the survival of larval herring. The initial hypothesis, that the reduction in larval survival during the reduced recruitment regime is associated with a change in growth rate, has been confirmed. The results, however, are limited to the 4 years considered, to the Buchan and Banks components in the first instance, and to larvae in the central North Sea. The exact mechanism via which the reduced growth rate causes a reduction in larval survival also remains unclear, although changes in the food supply are a likely candidate. However, this work also introduces a unique and new observation that any hypothesis needs to both incorporate and explain. This result therefore represents a significant milestone on the path to elucidating the mechanism underlying this challenging and enigmatic puzzle. 
Acknowledgements. The authors acknowledge the work undertaken by the crews, captains, and scientists who have taken part in the International Bottom Trawl Survey over the past $30 \mathrm{yr}$ and have been instrumental in collecting the source material used in this study. The authors also thank Morten Skogen of the Institute of Marine Research (IMR), Bergen, Norway, for providing the NORWECOM flow fields, and Audrey J. Geffen, University of Bergen, Norway and Mark Dickey-Collas, ICES, for inspiring conversations and constructive criticism. This study was funded in part by the EU project DefineIt under the MariFish ERA-NET (ERACCT- 2006-025989), and by the IMR North Sea program.

\section{LITERATURE CITED}

Aksnes D, Ulvestad K, Balino B (1995) Ecological modelling in coastal waters: towards predictive physical-chemicalbiological simulation models. Ophelia 41:5-36

> Alvarez-Fernandez S, Lindeboom H, Meesters E (2012) Temporal changes in plankton of the North Sea: community shifts and environmental drivers. Mar Ecol Prog Ser 462:21-38

Anderson JT (1988) A review of size dependent survival during pre-recruit stages of fishes in relation to recruitment. J Northw Atl Fish Sci 8:55-66

> Batchelder HP (2006) Forward-in-Time-/Backward-inTime-Trajectory (FITT/BITT) modeling of particles and organisms in the coastal ocean. J Atmos Ocean Technol 23:727-741

Brophy D, King PA (2007) Larval otolith growth histories show evidence of stock structure in Northeast Atlantic blue whiting (Micromesistius poutassou). ICES J Mar Sci 64:1136

Christensen A, Daewel U, Jensen H, Mosegaard H, St John M, Schrum C (2007) Hydrodynamic backtracking of fish larvae by individual-based modelling. Mar Ecol Prog Ser 347:221-232

Corten A (2013) Recruitment depressions in North Sea herring. ICES J Mar Sci 70:1-15

Cushing D, Bridger J (1966) The stock of herring in the North Sea, and changes due to fishing. Fish Invest, London, Ser II 25:1-123

de Figueiredo GM, Nash RDM, Montagnes DJS (2005) The role of the generally unrecognised microprey source as food for larval fish in the Irish Sea. Mar Biol 148:395-404

Dickey-Collas M, Nash RDM, Brunel T, van Damme CJG and others (2010) Lessons learned from stock collapse and recovery of North Sea herring: a review. ICES J Mar Sci 67:1875-1886

Edwards M, Johns D, Licandro P, John A, Stevens D (2007) Ecological Status Report 2005/2006. Results from the North Atlantic CPR survey: monitoring the health of the oceans using planktonic indicators. SAHFOS Tech Rep 4. Sir Alister Hardy Foundation for Ocean Science (SAHFOS), Plymouth

Fässler SMM, Payne MR, Brunel T, Dickey-Collas M (2011) Does larval mortality influence population dynamics? An analysis of North Sea herring (Clupea harengus) time series. Fish Oceanogr 20:530-543

> Folkvord A, Blom G, Johannessen A, Moksness E (2000) Growth-dependent age estimation in herring (Clupea harengus L.) larvae. Fish Res 46:91-103

Folkvord A, Johannessen A, Moksness E (2004) Temperature-dependent otolith growth in Norwegian spring- spawning herring (Clupea harengus L.) larvae. Sarsia 89: 297-310

Fox CJ, Folkvord A, Geffen AJ (2003) Otolith micro-increment formation in herring Clupea harengus larvae in relation to growth rate. Mar Ecol Prog Ser 264:83-94

Friedenberg LE, Bollens SM, Rollwagen-Bollens G (2012) Feeding dynamics of larval Pacific herring (Clupea pallasi) on natural prey assemblages: the importance of protists. Fish Oceanogr 21:95-108

Gallego A, Heath MR (1994) The development of schooling behaviour in Atlantic herring Clupea harengus. J Fish Biol 45:569-588

> Geffen AJ (1982) Otolith ring deposition in relation to growth rate in herring (Clupea harengus) and turbot (Scophthalmus maximus) larvae. Mar Biol 71:317-326

Heath M (1993) An evaluation and review of the ICES herring larval surveys in the North Sea and adjacent waters. Bull Mar Sci 53:795-817

> Heath M, Henderson E, Baird D (1988) Vertical distribution of herring larvae in relation to physical mixing and illumination. Mar Ecol Prog Ser 47:211-228

> Heath M, Scott B, Bryant AD (1997) Modelling the growth of herring from four different stocks in the North Sea. J Sea Res 38:413-436

> Hinder SL, Manning JE, Gravenor MB, Edwards M, Walne AW, Burkill PH, Hays GC (2012) Long-term changes in abundance and distribution of microzooplankton in the NE Atlantic and North Sea. J Plankton Res 34:83-91

Houde ED (2002) Mortality. In: Fiuman LA, Werner RG (eds) Fishery science: the unique contributions of early life stages. Blackwell Science, Hoboken, NJ, p 64-87

Hufnagl M, Peck MA (2011) Physiological individual-based modelling of larval Atlantic herring (Clupea harengus) foraging and growth: insights on climate-driven lifehistory scheduling. ICES J Mar Sci 68:1170-1188

ICES (2006) Report of the Planning Group of Herring Surveys (PGHERS), 24-27 January 2006, Rostock, Germany. ICES Document CM 2006/LRC:04

ICES (2012) Report of the Herring Assessment Working Group for the Area South of 62 N (HAWG), 13-22 March 2012, Copenhagen, Denmark. ICES CM 2012/ACOM:06

Johannessen A, Blom G, Folkvord A (2000) Differences in growth pattern between spring and autumn spawned herring (Clupea harengus L.) larvae. Sarsia 85:461-466

> Kiørboe T, Munk P (1986) Feeding and growth of larval herring, Clupea harengus, in relation to density of copepod nauplii. Environ Biol Fishes 17:133-139

> Leggett W, DeBlois E (1994) Recruitment in marine fishes: is it regulated by starvation and predation in the egg and larval stages? Neth J Sea Res 32:119-134

McGurk M (1984) Ring deposition in the otoliths of larval Pacific herring, Clupea harengus pallasi. Fish Bull US 82: 113-120

McGurk M (1986) Natural mortality of marine pelagic fish eggs and larvae: role of spatial patchiness. Mar Ecol Prog Ser 34:227-242

Montagnes DJS, Dower JF, Figueiredo GM (2010) The protozooplankton-ichthyoplankton trophic link: an overlooked aspect of aquatic food webs. J Eukaryot Microbiol 57:223-228

> Mosegaard H, Svedäng H, Taberman K (1988) Uncoupling of somatic and otolith growth rates in Arctic char (Salvelinus alpinus) as an effect of differences in temperature response. Can J Fish Aquat Sci 45:1514-1524

Munk P, Heath M, Skaarup B (1991) Regional and seasonal 
differences in growth of larval North Sea herring (Clupea harengus L.) estimated by otolith microstructure analysis. Cont Shelf Res 11:641-654

Nash RDM, Dickey-Collas M (2005) The influence of life history dynamics and environment on the determination of year class strength in North Sea herring (Clupea harengus L.). Fish Oceanogr 14:279-291

Payne MR (2010) Mind the gaps: a state-space model for analysing the dynamics of North Sea herring spawning components. ICES J Mar Sci 67:1939-1947

Payne MR, Hatfield EMC, Dickey-Collas M, Falkenhaug T and others (2009) Recruitment in a changing environment: the 2000s North Sea herring recruitment failure. ICES J Mar Sci 66:272-277

$>$ Pepin P (1991) Effect of temperature and size on development, mortality, and survival rates of the pelagic early life history stages of marine fish. Can J Fish Aquat Sci 48: 503-518

Pinheiro JC, Bates DM (2000) Mixed-effects models in S and S-PLUS. Springer Verlag, New York, NY

Sinclair M (2009) Herring and ICES: a historical sketch of a few ideas and their linkages. ICES J Mar Sci 66:

Editorial responsibility: Konstantinos Stergiou,

Thessaloniki, Greece
1652-1661

Skogen MD, Søiland H (1998) A users guide to NORWECOM 2.0: the Norwegian Ecological Model System. Fisken Havet 18:1-42

Skogen MD, Svendsen E, Berntsen J, Aksnes D, Ulvestad KB (1995) Modelling the primary production in the North Sea using a coupled three-dimensional physical-chemical-biological ocean model. Estuar Coast Shelf Sci 41: 545-565

Thygesen U (2011) How to reverse time in stochastic particle tracking models. J Mar Syst 88:159-168

> Weijerman M, Lindeboom H, Zuur A (2005) Regime shifts in marine ecosystems of the North Sea and Wadden Sea. Mar Ecol Prog Ser 298:21-39

Wood SN (2006) Generalized additive models: an introduction with R. Chapman Hall / CRC Press, Boca Raton, FL

Zuur A, Ieno E, Walker N, Saveliev A (2009) Mixed effects models and extensions in ecology with R. Springer, New York, NY

> Zuur AF, Ieno EN, Elphick CS (2010) A protocol for data exploration to avoid common statistical problems. Method Ecol Evol 1:3-14

Submitted: November 2, 2012; Accepted: April 29. 2013 Proofs received from author(s): August 20, 2013 